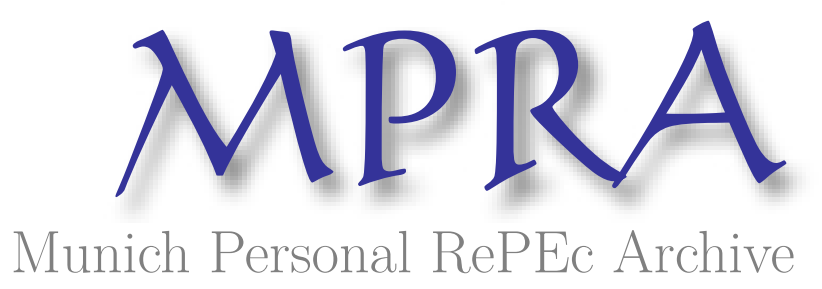

\title{
A note on the valuation of collective goods: overlooked input market free riding for non-individually incrementable goods
}

Graves, Philip E.

University of Colorado

2009

Online at https://mpra.ub.uni-muenchen.de/19928/

MPRA Paper No. 19928, posted 14 Jan 2010 00:06 UTC 


\section{Introduction and Motivation}

For pure public goods, Samuelson (1954) showed that optimal provision levels would result if individual willingness-to-pay were aggregated (added vertically, in a graphical setting) to arrive at marginal benefits to be compared to marginal provision costs. This follows from the non-rivalrous nature of public goods; any individual receiving benefits does not reduce the benefits received by others. Aggregating in this manner would, he argued, result in levels of public goods provision exactly paralleling the desirable efficiency conditions typically associated with perfectly-functioning private markets.

Samuelson was aware that the application of his recommended methodology for optimal public goods provision would be very difficult in practical policy settings. True aggregate marginal willingness to pay will be difficult to infer, since each individual has an incentive to understate preferences when asked to contribute. This is the well-known (output) demand revelation, or "free rider," problem for public goods, due to inability to exclude users, that has been addressed under somewhat restrictive conditions elsewhere (see Clarke 1971, Groves and Ledyard 1977).

However, since Samuelson correctly interpreted inputs as negative outputs, assigning them a minus sign, the traditionally recognized output demand revelation problem also implicitly embeds an input demand revelation problem that has gone unrecognized. That is, we work to acquire the goods we desire, and if an increment to work effort does not allow an increment to consumption of the goods we desire, that increment to work effort will not take place-because leisure is valuable. This input demand revelation problem has been ignored in both theoretical discussion and in all applied benefit-cost valuation work for the case of public goods. In much of what follows I will assume that the output demand revelation problem as traditionally discussed has been solved, although that is not important to the argument. ${ }^{1}$

Motivating the discussion of the following sections, consider two types of individuals. The first, Ben Shoppin, desires mega-mansions, expensive sports cars, foreign vacations, designer clothing, gourmet restaurant meals, and fine wine. Ben realizes that he has three options for achieving his goals, only one of which is practical. He could hope that someone will give him what he wants or perhaps that he could steal what he wants. Absent philanthropy or theft, however, Ben will realize that the only way to obtain his desired goods is to generate the

Since this problem is unlikely to be solved in practice (requiring quasi-linear preferences, and the like), further weight is added to the arguments of the main text that current provision levels of certain public goods are likely to fall short of socially optimal levels. For a host of arguments, most unrelated to the present discussion, that suggest that decision-makers are likely to underprovide public goods see Graves 2007. 
income necessary to acquire them. The critical observation for present purposes, however, is that if Ben generates the income, he knows that he can in fact acquire what he wants, because what he wants are ordinary private goods.

Now consider Sten (for strong environmentalist). What Sten cares most about are more wilderness areas, cleaner air and water, reduced $\mathrm{CO}_{2}$ build-up, species preservation, and so on. ${ }^{2}$ He has quite limited desires for ordinary private goods. Sten differs importantly from Ben because the former will realize, if rational, that any income generated to acquire the public goods that he desires will be negligible in that collectively-determined decision. Since Sten cannot get what he wants by giving up leisure, and since leisure is valuable, Sten will only generate the income necessary to buy the limited range of private goods he desires (and to pay for the costs, in terms of taxes or higher prices, of whatever amount of public goods are provided collectively). In extreme cases, Sten and others like him might "drop out" in the jargon of " 60 s hippies. ${ }^{3}$ But even in a world of homogeneous preferences involving relatively low demands for public goods, the inability to individually increment public goods will result in nonoptimally low income generation. ${ }^{4}$

Further clarifying, consider two individuals who are observed to generate fairly low, but identical, levels of income. One is "lazy," in the vernacular, valuing leisure and not caring greatly for goods of any kind, private or public. The other cares a great deal about public goods of various kinds and other goods that are determined collectively-but she recognizes that any income that she

I am focusing on environmental goods in the text, rather than say national defense, for two reasons. First, abstracting from cost, environmental goods would have positive or at least zero marginal values to all. National defense, and certain other public goods, might on the margin be "bads" for many individuals, complicating a bit the direction of the bias in income generation discussed here. Second, in the case of national defense (and certain other collectively provided goods) special interest political influence might also render the direction of provision bias uncertain.

It should be noted that a) some individuals with pronounced social consciences might work more than would normally be considered rational in this case, b) some individuals will volunteer in an effort to make a difference in that way, and c) some individuals will work in the political arena to acquire what they think socially desirable. In all cases, however, they will do less than is socially desirable, if rational, because personal costs will be large relative to personal benefits for all such actions.

Were preferences homogeneous it is, of course, much more likely that the political outcome would be nearer the true Samuelson optimum optimorum than is the case with large variations in both preferences and human capital. 
might generate would have a negligible impact on what she cares about. To the economist, these two individuals are observationally equivalent in that neither person looks like they have much marginal willingness-to-pay for anything, despite the latter's strong desires for public goods.

As one last motivating example, ${ }^{5}$ suppose the link between work effort and work reward were to be broken for ordinary private goods. Imagine, specifically, that an extreme egalitarian communist regime were to decide that everyone will receive exactly $\$ 500$ per month of goods and services; they must generate income to pay for those goods and services but cannot acquire more than that quantity, regardless of their income. How much income will a rational worker generate in such a system? Regardless of their true marginal willingnessto-pay for goods and regardless of how little they might value leisure relative to goods, they will only generate $\$ 500$ per month of income.

The productivity of the collective farms of the old Soviet Union was very low relative to that of the small privately owned farms. Pundits argued at the time that this was because the link between work effort and work reward was largely broken for the former, but not for the latter. But, public goods (and nonindividually incrementable goods more generally) represent, even in aggressively free market private good economies, a similar-indeed a more extreme-case in which the link between work effort and work reward is severed.

The text examples are designed to clarify what this paper is not about. Some reviewers of earlier versions thought that the point was merely that, in general equilibrium, increments to the public good would result in revised optimal work-leisure decisions. While this is true (see Flores and Graves 2008 for further formal details), that effect may be of $2^{\text {nd }}$ order importance, particularly if benefit-cost analysis of public goods is conducted with sufficient frequency and for sufficiently small increments. Moreover, the paper is not about complementarity, substitutability or separability conditions among all goods consumed; only in unrealistic extreme cases would that have any important impact on the free riding argument. Further, the discussion has nothing to do with the ordinary (or tax-distorted) elasticity of labor supply with respect to the wage rate-that relationship is shifted by the free riding in input markets discussed here. Finally, while the omission of the input demand revelation problem is more obvious if one does not employ a full income constrained utility model, employing such a model does nothing to eliminate the free riding behavior in either output or input markets. The point of the paper is that there will always be input market free riding any time that conditions lead to the traditionally recognized output market free riding behavior (people will not work if they are unable to increment a class of goods they desire by doing so). Input market free riding is completely symmetric to-indeed embedded in-the oft-discussed output demand revelation problem. 


\section{The Input Demand Revelation Problem}

As mentioned above, in his 1954 discussion, Samuelson indicated that inputs can be handled just like outputs, but with a minus sign preceding them. This implies, as indicated in the introductory examples, that embedded in the traditionallyrecognized output demand revelation problem are input market demand revelation difficulties. Whenever conditions (non-excludability and non-rivalry in consumption, in the case of pure public goods) lead to an output market failure, there will be a concomitant input market failure ("free riding" in input markets). The latter problem has been ignored in practical public policy settings, with the income at which benefit-cost analyses of public goods are conducted being implicitly taken to be optimal when it is in fact non-optimally low.

For ordinary private goods one would certainly expect that there would be neither an output demand revelation problem nor an input demand revelation problem. Indeed, as is well-known, a full-income model of rational individual behavior recognizes that individuals will attempt to balance their goods demands with their leisure demands, so that the utility gain from goods purchased with the after-tax wage from the last hour worked exactly balances the utility value of the foregone leisure to get those goods. We work, in short, to get the things we want.

But suppose as with the introductory examples we cannot get, on the margin, what we want by working? Consider in particular the leisure choices that result from desires for pure public goods. Regardless of the extent of a rational individual's desire for a pure public good, each person will recognize that any income generated to acquire it will be inconsequential; the public good outcome is collectively determined, and this is well-known to every individual. Since leisure is both scarce and valuable, the typical person who cares about public goods-everybody to varying degrees-will generate too little income. ${ }^{6}$ They will equate the marginal value of leisure to the marginal value of private goods, but not to the marginal value of public goods, since they cannot individually increment public goods.

Consequently, using benefit-cost analysis to value pure public goods implicitly starts with a given income that is presumed optimal when it is, in

In the heterogeneous preferences case, it is likely that even a quantity of the public good that is very socially sub-optimal will be "too much" for some individuals, perhaps the poor and healthy in the context of the environment. For those individuals, the income under-generation argument of the text evaporates; the input demand revelation problem in this case becomes a "non-binding disincentive." 
general, sub-optimal. ${ }^{7}$ Moreover, all of the ungenerated income would, apart from general equilibrium effects, have been devoted to the public good (since there is no incentive to under generate income to buy ordinary private goods). If aggregated marginal willingness-to-pay out of current income appears to just equal marginal provision cost, the benefit-cost analyst will presume an optimum exists when too little of the public good is being provided.

\section{An Illustrative Model}

Consider a simple Cobb-Douglas formulation of the representative household's utility in a three-good world with ordinary goods, X (taken to be the numeraire), leisure, L, and the public good, G, which might be thought of as environmental quality: ${ }^{8}$

1) $\quad \mathrm{U}=A X^{\alpha} \mathrm{L}^{\beta} \mathrm{G}^{\gamma}$

This is to be maximized subject to the weekly full-income budget constraint $168 \mathrm{w}=\mathrm{X}+\mathrm{wL}+\mathrm{tG}$, where $\mathrm{w}=$ real wage, $\mathrm{t}=1 / \mathrm{nT}$ with $\mathrm{n}$ being the number of households and $\mathrm{T}$ being the marginal cost of providing the public good. As is well-known for the Cobb-Douglas, solving the first order conditions for the optimal quantities, expressing them in terms of leisure, and substituting into the budget constraint results in $168 \mathrm{w}=\mathrm{w} \alpha \mathrm{L} / \beta+\mathrm{wL}+\mathrm{w} \gamma \mathrm{L} / \beta$. If, say, $\alpha=.3$, $\beta=.6$ and $\gamma=.1$ and taking wage to equal $\$ 10$ for simplicity, $L^{*}=100.8$ hours at the social optimum. This implies that workers are earning $(168-100.8) \mathrm{w}$, or $\$ 672 /$ week to pay for the optimal quantities of goods, leisure, and the public

It would be implausible to suggest that decision-makers might accidentally hit upon the one true Samuelson optimum optimorum, resulting in optimal work-leisure decisions. To do so would require, even with perfect demand revelation out of current income, that decision-makers accept public good projects with costs in excess of apparent benefits (out of existing income) by the amount of the ungenerated income that would have been devoted to public goods were individuals able to purchase them as ordinary private goods. As with the traditional demand revelation problem, individuals have no incentive to accurately reveal that information to analysts.

It should perhaps be noted that the labor/leisure decision will also generally be affected by the introduction of new goods. Technological changes that result in a desirable new good will result in greater work effort, while technological changes that lower the prices of existing goods will result in reduced work effort. Endogenous growth models do not yet allow for endogenous variation in labor supply, yet doing so would provide a deeper understanding of the business cycle as well as better clarifying the nature of GDP as a measure of welfare. Additionally, the acquisition of human capital will be biased downward to the extent that a) we educate ourselves to acquire the goods we want, and b) some of those goods are not individually incrementable. Furthermore, the disincentive discussed here should result in at least some bias upward in the social rate of discount; bequests are likely to be smaller since the saver will realize that his/her heirs will be unable to individually increment desirable public goods. 
good.

However, the analyst does not observe Equation 1). In the simple CobbDouglas case, the larger is $\gamma$ the more leisure is purchased-if this parameter takes on the value of .1, then rational individuals would "buy" ten percent more leisure, since expenditure shares equal the coefficients on the arguments of the utility function. ${ }^{9}$ Hence, the free riding behavior in input markets of interest here implies that the regulatory authority would observe the utility of the representative household as being:

2) $\quad U=A X^{\alpha} L^{\beta} G^{0}=A X^{\alpha} L^{\beta}$

The problem is that $\mathrm{G}^{\gamma}$ in Equation 1) is not only an unknown optimal quantity, but one that individuals have no incentive to reveal in their observable behavior, as the introductory examples clarify. Individuals in maximizing Equation 2) will buy more leisure $(168 w=w \alpha L / \beta+w L$, which, for the same parameters as assumed above, results in optimal leisure of 112 hours). Hence, workers will only work 56 hours generating $\$ 560 /$ week to buy the "optimal" quantities of private goods and leisure-these being the only two things they can individually buy. Since the leisure coefficient in Equation 1) is twice that of private goods (and plausibly could be even relatively larger, in light of the large number of hours worked with those parameters), a ten percent increase in leisure results in a twenty percent reduction in income generated ( $\$ 112$ is twenty percent of $\$ 560)$.

The intuition of this result is perhaps easiest to understand in comparing the last expression in Equation 2) to Equation 1)-it is as if another desirable ordinary private good has been introduced in the latter. The existence of another valuable good implies cutbacks on quantities of the existing goods, and upon leisure, until the equi-marginal principle applies to all three goods entering the utility function. This does not happen for public goods because they cannot be individually incremented as emphasized in opening examples.

Initially, private goods and leisure are likely to be of primary concern in the context of a typical developing economy, with demands for public goods coming later. Moreover, "natural" supplies of the public good (e.g. hunting rifles for national defense or large initial stocks of environmental resources) might exceed initial demands at low population and income levels. Hence, initial marginal willingness to pay might be near zero, at relatively large naturally

Suppose, for example, that a thousand homogeneous residents of a seaside village each had a net present value for a lighthouse of $\$ 2,000$ with the Cobb-Douglas utility coefficient being . 1 for the lighthouse. If the lighthouse can be created for a net present cost of one million dollars, it should, of course, be produced. With free riding, it will not, however, get produced and each resident of the village would generate $\$ 2,000$ less income under independence. 
present $\mathrm{G}$ values. One would expect, however, that the demand for the public good would continually grow relative to the (possibly decreasing) supply until it exceeds initial supply by enough to create a collective desire for intervention, at least in a democratic economy. When such a critical mass is achieved, an institution will be brought into existence (e.g. creation of the EPA in 1970 in the U.S.) to provide appropriate levels of the public good. ${ }^{10}$

How can the regulatory institution determine, in such cases, how much of the public good to supply, when they observe Equation 2) but would like to observe Equation 1)? As a practical matter, they are likely to begin conservatively, supplying initially a relatively small amount of the public good, $\mathrm{G}_{0}$, with early environmental regulations being representative. In an "ideal" world, at least from an economist's perspective, they would like to supply the traditionally-defined socially optimal quantity, $\mathrm{G}_{0}{ }^{*}$, which would likely exceed $\mathrm{G}_{0} \cdot{ }^{11}$

The traditional output demand revelation problem clarifies why it would be difficult to infer the true parameters of Equation 1) from the "information" in Equation 2), because each representative agent has an incentive to understate their output demands, as is well-known. It will be very difficult to determine the value of $\mathrm{G}_{0} *$.

But-even if regulators were somehow able to know true demands from a given income, hence $\mathrm{G}_{0}{ }^{*}$-those aggregated demands are being calculated at the wrong income level, as seen in the simple Cobb-Douglas case. The representative households will alter their levels of leisure and private goods in response to the provision of $\mathrm{G}_{0}{ }^{*}$, but only to the extent that they must pay higher prices or taxes

10

How early in the existence of a country various institutions will come into existence would depend on the nature of the public good. This might happen quite early for national defense in a dangerous world, somewhat later for roads, lighthouses and the like and much later still for goods such as environmental quality that might have been in great abundance relative to private goods initially. The Cobb-Douglas case, with no "choke-price," would lead to earlier political interventions, though this is perhaps an unrealistic utility specification for many public goods.

1

The real world is considerably more complicated in that preferences are heterogeneous, with differing intensities of demand for the public good. If $\mathrm{n}$ representative households each paid $1 / \mathrm{n}$ of the marginal provision cost, political outcomes might fairly quickly come to more closely approximate the true Samuelson optimum optimorum. Referenda are unlikely in practice to solve the problem raised here, in light of heterogeneity of preferences and income. 
at that provision level. ${ }^{12}$ Households still have no incentive to reveal how much more they would work for increments to the public good, even if they have very high marginal value at $\mathrm{G}_{0}{ }^{*}$, because they cannot individually increment the public good.

The situation is illustrated in Figure 1. The level of public good provision is on the horizontal axis, while marginal benefits and marginal provision costs are on the vertical axis. The $\mathrm{MB}_{\text {True }}$ curve represents the (unobserved) aggregate marginal-willingness-to-pay for the public good when there is neither the traditional output demand revelation problem nor the input demand revelation problem emphasized here. It shows the marginal willingness-to-pay if people could increment the public good by their individual decisions to generate income, as they can with ordinary private goods. Leisure and ordinary goods consumption are, in other words, being optimally varied (from society's perspective) by individuals along $\mathrm{MB}_{\text {True }}$ at various hypothetical levels of collectively determined public good provision, $\mathrm{G}$. If larger levels of $\mathrm{G}$ are provided, financed either by taxes or higher private goods prices, one would expect that households would react by consuming smaller levels of private goods and leisure, in some mix.

However, holding leisure fixed at any level results in steeper conditional marginal-willingness-to-pay curves. Consider the case of an increment to the public good. The marginal value of the public good will appear to the benefitcost analyst to fall more rapidly (the value of foregone ordinary private goods will rise more rapidly) when households do not reduce their leisure to obtain greater income than would be the case if they exercised that option. Similarly, for decrements to the public good, being constrained to have a larger than optimal income implies that households would be willing to give up more goods to avoid that decrement. ${ }^{13}$

There will be an infinite number of leisure-fixed marginal willingness-topay curves (two being shown in Figure 1). Each such curve possesses one point at which the fixed leisure constraint is non-binding, where the curve intersects $\mathrm{MB}_{\text {True }}$. That is, at each level of the public good there will be one level of fixed

\footnotetext{
More sophisticated functions could allow for complementarity or substitutability among the three goods entering household utility, modifying quantitative conclusions; but the underlying input demand revelation problem remains-a discrete disincentive to work remains when working does not allow individual households to get more of what they want.

13

This would be one reason for the frequent finding in the experimental economics literature that WTA is larger than WTP, since these values are taken at current incomes not at the incomes that would actually be generated if the public good were decremented or incremented. The current discussion complicates this endogeneity point in that WTP is itself too low because of input market free riding.
} 
leisure will also corresponds to the optimal leisure for that public good level.

In the figure, were there neither output demand nor input demand revelation problems, the regulatory authority would clearly produce $\mathrm{G}_{\text {True }}{ }^{*}$, the public good level at which true marginal benefits equal marginal provision costs, the one true Samuelson optimum optimorum.

Now, oppositely, assume the presence of the traditional demand revelation problem. In this case, rational decision makers are unwilling to reveal their true demands for public goods because they know they cannot be excluded from consuming whatever happens to be provided anyway, and that any revealed demands would negligibly effect the provision level. Moreover, assume that these rational people also will not give up valuable leisure to generate income to buy things that they cannot individually acquire by doing so, the input demand revelation problem that is embedded in the traditional output demand revelation problem. In other words, consider the extreme polar case of the situation that would give rise to the true optimum. Self-interested individuals are generating the wrong income level and they are unwilling to reveal what public goods are worth to them at that wrong income level. In this extreme situation, the provision level for the public goods will initially be zero, since there will appear to be no demand whatsoever for such goods, as reflected in Equation 2) above.

Eventually, as discussed earlier, the growing gap between the true marginal benefits and the marginal costs of the public good will result in regulation via the political system (e.g. creation of the EPA, passage of an Endangered Species Act, Kyoto agreements, etc.). ${ }^{14}$ A positive quantity of the public good will be provided, either directly by government or by a regulated private sector, with taxes or prices rising as a consequence. The initial provision level is unlikely to be optimal according to any analytical benchmark.

However, while not of importance to the argument, suppose that the regulators have managed to stumble upon a mechanism that accurately reveals aggregate demand out of current income-a mechanism that does not, however, solve the input demand revelation problem of interest here. The dashed curve labeled $\mathrm{MB}_{\mathrm{Apparent}}$ in Figure 1 depicts the marginal benefits observed by the regulatory authorities in this situation, and presumably they would wish to provide $\mathrm{G}_{0}$ * of the public good, abstracting from any public choice disincentives to do so.

14

The gap discussed in the text will be getting larger over time with a positive-and perhaps superior-ordinary income elasticity of demand for the public good, creating ever-increasing political pressure to intervene. Individuals will come to realize that, while it is irrational to individually pay, it might be rational to force everyone to pay as the gap gets larger. 


\section{A False and a True Dynamic Scenario}

If there were no input demand revelation problem, individuals would reoptimize leisure and private goods from their levels at a zero provision level to those appropriate to $\mathrm{G}_{0}{ }^{*}$ public good provision level, consuming fewer private goods and "buying" less leisure (working harder). Hence, the regulators would now, in principle, see a larger demand for the public good, shown as $\mathrm{MB}_{\mathrm{L}^{*} 1}$ in Figure 1. $\mathrm{MB}_{\mathrm{L}^{* 1}}$ is the marginal benefit when leisure is constrained to the level appropriate to a $\mathrm{G}_{0}$ * provision level, hence it falls faster with $\mathrm{G}$ than does the marginal benefit when leisure is optimally varied as discussed in Section III. Should the regulatory authorities conduct another benefit-cost analysis, one might expect that they would then find it optimal to provide $\mathrm{G}_{1}$ * of the public good. At this point, individuals would again reoptimize, resulting in a new marginal benefit curve, $\mathrm{MB}_{\mathrm{L}^{*} 2}$, which in turn would prompt the regulatory authority to provide more of the public good, at $\mathrm{G}_{2} *$ in the figure.

This process might be expected to continue if benefit-cost analyses were conducted for reasonably small increments to the public good. If additionally these analyses were conducted with some frequency, one might expect that actual outcomes would come to approximate the true social optimum in Figure 1. The process described would seem to lead inexorably toward the optimum optimorum depicted in the figure, with luck approximating it after perhaps only a few benefit-cost iterations.

The preceding discussion of the dynamic process essentially endogenizes the labor supply decision as it relates to public goods provision in a 3-good world of leisure, private, and public goods (see Flores and Graves 2008, for further details). But this description of the dynamic process errs in presuming that individuals will reoptimize their leisure and other goods consumption when $\mathrm{G}_{0}$ * is provided. Indeed, this is the whole point of the input demand revelation problem-individuals will only work to pay the higher costs associated with $\mathrm{G}_{0}{ }^{*}$. The regulatory authorities do not observe $\mathrm{MB}_{\mathrm{L}^{*} 1}$ when the public good is provided at the $\mathrm{G}_{0}{ }^{*}$. Rather they continue to only observe the $\mathrm{MB}_{\text {Apparent }}$ curve. In going from zero to $\mathrm{G}_{0}{ }^{*}$, households decrease leisure (and ordinary goods consumption) somewhat to pay the higher taxes or prices associated with having $\mathrm{G}_{0}{ }^{*}$. Critically, however, as with any project offering future benefits, those public good benefits can only be obtained after first incurring costs (e.g. installing add-on control devices, prior to receiving cleaner air). Any adjustments to income (changes in leisure) and private goods consumption that households would deem optimal as a result of the costs of providing higher levels of the public good will also be made prior to arriving at $\mathrm{G}_{0}{ }^{*}$. Rational agents will make no further adjustments, free riding in input markets even if (aggregated) marginal individual values greatly exceed marginal provision costs. 
The vertical distance from $\mathrm{MB}_{\text {Apparent }}$ to the $\mathrm{MB}_{\text {True }}$ curve represents the (unknown) extent of the input demand revelation problem. Were the output demand revelation problem more important than the input demand revelation problem, $\mathrm{MB}_{\text {Apparent }}$ would be located further to the right of its hypothetical location in Figure 1. In such a case, the vertical distance to the $\mathrm{MB}_{\text {True }}$ curve-the input demand revelation problem of focus here-would be smaller. However, the regulatory authority inevitably only observes a portion of the true demand (assuming quite optimistically that the output demand revelation problem has been solved at some initial income level).

The labor-leisure endogenization process described in the first two paragraphs of this section will, then, be short-circuited. If the regulatory authority were to consider going from $\mathrm{G}_{0}{ }^{*}$ to $\mathrm{G}_{1}{ }^{*}$, the costs would appear to be greater than the benefits, and that movement would be (wrongly) rejected.

The true marginal benefit curve, for normal or superior public goods such as environmental quality, is itself shifting out over time. Rising real income due to technological advances and innovations (most likely for ordinary private goods for obvious excludability reasons), by increasing the relative abundance of private goods will cause a shift to the right of both $\mathrm{MB}_{\text {True }}$ and $\mathrm{MB}_{\text {Apparent }}$, still presuming the traditional output demand revelation problem to be solved. However, assume for a moment that the relative importance of the output demand revelation problem and the input demand revelation problem remains constant at higher income levels. A ten percent increase in $\mathrm{MB}_{\text {True }}$ will lead to a ten percent increase in each component, but only the output demand revelation problem is assumed solved. Hence, the rightward shift in $\mathrm{MB}_{\text {Apparent }}$ will be smaller in absolute terms than the overall shift in true marginal willingness to pay. In other words, it is not clear that "apparently-optimal" provision levels, derived from benefit-cost analyses at current income levels, are even getting relatively closer to the (moving) true optimum optimorum over time.

In the real world, of course, decisions get made and are not revisited with great frequency. ${ }^{15}$ So a suspicion (returned to in the conclusions) is that we might be getting further from many public goods optima, despite progress in the sense that many public goods levels are increasing. Hence, as a practical matter public goods are likely to be under-provided employing standard benefit-cost techniques, even with the unrealistic assumption of perfect output demand revelation.

15

Infrequent decision-making would suggest that both the failure to endogenize the labor/leisure decision (see Flores and Graves 2008) and the input market free riding problem emphasized here will work in the same direction, increasing the under-provision of public goods. 


\section{Concluding Thoughts-Much Ado About Nothing?}

What is the potential importance of the input demand revelation problem discussed here? It is certainly the case that the $\mathrm{MB}_{\text {Apparent }}$ curve in Figure 1 could have been drawn to represent a larger proportion of $\mathrm{MB}_{\text {True }}$. There is, however, much suggestive evidence that would imply that too few resources are being devoted to certain public goods. A first observation is that very small alterations in leisure result in income changes that are quite large relative to current spending on most public goods.

Illustrating with the case of environmental quality in the United States, Freeman $(2002$, p. 126) has calculated that the U.S. spent at the time of his study roughly $\$ 225$ billion annually on all major environmental programs instituted since 1970, say $\$ 280$ billion in current dollars. A mere one-percent increase in income generated to go toward such environmental goods would amount to $\$ 140$ billion at a current $\$ 14$ trillion U.S. GDP. Solving a input demand revelation problem of even such small hypothetical magnitude would result in a 50\% increase in resources devoted to environmental public goods provision, and a substantially improved environmental quality, even with rising marginal provision costs.

Additionally, a robust finding in experimental economics is that decision-makers often exhibit a much smaller dollar willingness-to-pay (WTP) for an item than the minimum amount that they claim to be willing to accept (WTA) to part with it (see Horowitz and McConnell 2002 for a survey of 45 studies). Indeed, Sugden (1999) argues that the observed discrepancies between WTA and WTP are so large as to be inconsistent with neoclassical preferences. That WTA is large relative to WTP has been sometimes attributed to an "endowment effect" (see Kahneman, et al. 1990, Twersky and Kahneman 1991) in somewhat ad hoc, non-utility-based discussions. There may well be merit in their explanation, and perhaps other explanations, for the WTA-WTP gap (see Boyce et al. 1992 or Hanemann 1991) and it is even possible that the gap does not exist for ordinary private goods (see Plott and Zeiler 2007, who argue, employing private good experiments, that the WTA-WTP gap is illusory, due to flawed analysis).

However, Horowitz and McConnell's observation that the WTA-WTP gap is by far the largest for public goods, suggests the possible importance of the arguments presented here. For example, when contemplating small increments to air quality people will often express quite small marginal willingness-to-pay, but will claim to require order-of-magnitude larger amounts to compensate for equally-small decrements to air quality. The ungenerated income resulting from the input market demand revelation problem would add to the WTP, greatly reducing the gap, and suggesting that WTA, might more closely approximate 
properly measured WTP. ${ }^{16}$

The arguments here may also account for seemingly "faulty" environmental perceptions, perceptions that certain conditions are worsening when official data would suggest that they are improving. For example, a large majority of surveyed Americans believe US air quality is deteriorating, while less than one out of four believe that air quality has gotten "better" in recent decades, despite average reductions of 77 million tons per year of EPA criteria pollutants. Clear improvements in environmental measures are being perceived as deterioration. While there may be competing hypotheses (e.g. bias introduced by environmental groups or the liberal media), it is possible that "more feels like less"-that we are doing "better" in absolute terms, but worse in relative terms. The growth in real income, and hence consumption of private goods, may well have lowered private good values relative to public good values. It is, of course, relative values that matter in economics.

One might counter the preceding arguments by claiming that Americans, and Europeans to a lesser extent, work long hours already, hence would be unlikely to be willing to work still harder to obtain higher levels of public goods such as environmental quality. The discussion of most of this paper has implicitly assumed, to focus on the symmetric free riding behaviors, that the public good is independent of leisure and private goods. It is clear, however, that households in all countries do generate a great deal of income to buy private good substitutes for improperly provided public goods. Focusing on the case of "location-fixed" public goods, one might argue that non-optimal suburbanization has occurred because of failure to properly provide school quality, low crime, park space and the like in our urban centers. Hence optimal provision of such goods need not necessarily result in a greater net work effort, since costly commuting can be avoided and desirable urban amenities such as culture or restaurant diversity, can be consumed at lower expense were public goods properly provided at the urban center.

But the general point remains: only if perfect private good substitutes existed for all public goods would households generate the correct amount of income and receive the correct amounts of private and public goods (private and public not being distinguishable in this case). This is highly implausible.

Another counter argument to the importance of the observations being

\footnotetext{
16
}

In stated-preference studies, people routinely claim larger values than seem plausible at their income level (but note that current income is what is elicited, when it is the income that would be earned to acquire the good in question that is of relevance). That is, it is possible that the stated preference results are closer to the "truth" than previously thought, with actual behavior "false" because of the input demand revelation problem for public goods. See, however, footnote 13 for an argument that WTA is biased upward, at least somewhat, by the failure to allow for reduced income generation in the presence of a public good decrement. That is, if a public good is decremented the individual will have an incentive to increase leisure, but from an already non-optimally high leisure level. 
made here is that pure public goods are comparatively rare. Most of the goods we care about are private, hence the welfare loss from even substantial underprovision of public goods might be small. However, any collectively provided good, whether a pure public in the classic sense or not, will suffer from the problems discussed here, since individuals are unlikely or unable to increment such goods individually.

Moreover, the input demand revelation problem will be present for any good for which "non-use" value is a significant component of overall value, of particular interest in the environmental context. Consider impure public goods many of which, while non-excludable, are rivalrous. The use values for such goods may be reflected in resource allocation decisions, as emphasized by Coase (1960). Non-use values, however, will be understated because of both traditional output demand revelation difficulties and the input demand revelation problems.

Particularly noteworthy are contentious issues of preservation (cut the oldgrowth forests versus preserve them, drill for oil or natural gas versus preserve pristine areas, drive a species to extinction versus preserve it, maintenance of $\mathrm{CO}_{2}$ levels, and so on). Such controversies often involve clashes among the relatively few with high private use values and the many with non-use values of varying magnitude. Since rational individuals in the latter group will know they are too small to make a difference, they will neither give up leisure to generate income for preservation nor accurately reveal willingness to pay given the income generated. The resources are much more likely to be allocated to their use values a la Coase, when perhaps that would be non-optimal in many cases.

The implications for the practical relevance of the Coase theorem are clear: both the traditional output demand revelation difficulty and the input demand revelation difficulty discussed here are likely to result in inefficient resource allocation when non-use values are important for any good. Indeed, whether a forest is privately-owned or publicly-owned, the non-use values might in some cases swamp in magnitude the use values, leading to resource misallocation when the non-use values are mismeasured, due to either output demand or input demand revelation problems. It seems exceedingly unlikely that both problems can be surmounted in practical policy settings. ${ }^{17}$

As mentioned briefly earlier, real income (output) has risen dramatically over time in the developed world. This implies that marginal values of ordinary goods will have fallen relative to marginal values of public goods and goods with important non-use value. The gap between the growing optimal provision of public goods and their actual provision may well be increasing not decreasing, despite cases of measured progress (e.g. those controversially documented by

It should perhaps be noted that existing solutions to the output demand revelation problem require quasi-linear preferences which would appear to be particularly restrictive in light of the input demand revelation problem emphasized here. 
Lomborg 2001).

In closing, the discussion here naturally leads to the policy-critical question: "How do we proceed when we do not know how much income would in fact have been generated if households could buy public goods as they can ordinary private goods?" Without specific knowledge of the full income utility functions of a generally heterogeneous population, we appear to be in a bind, a bind complicated by the fact that individuals have incentives in both input and output markets to hide their true preferences. Though speculative, one possibly fruitful approach might be to increase public goods provision levels until their WTA/WTP ratios approach the much lower ratios observed for ordinary private goods.

\section{References}

Boyce, R. R., T. C. Brown, G. H. McClelland, G. L. Peterson and W. D. Schulze (1992). An experimental examination of intrinsic values as a source of the WTA-WTP disparity. American Economic Review 82(6), 1366-1373.

Clarke, E.H. (1971). Multipart Pricing of Public Goods. Public Choice. 11, 17.

Coase, R. (1960). The Problem of Social Cost, Journal of Law and Economics. October, 1-44.

Flores, N.E. and P.E. Graves (2008). Optimal Public Goods Provision: Implications of Endogenizing the Labor/Leisure Choice. Land Economics, 84(4), 701-707.

Freeman, A. M. III, (2002). Environmental policy since Earth Day I: What have we gained? The Journal of Economic Perspectives. 16, 125-146.

Graves, P.E. (2007). Environmental Economics: A Critique of Benefit-Cost Analysis. New York: Rowman \& Littlefield, 187pp.

Groves, T and J.O. Ledyard (1977). Optimal Allocation of Public Goods: A solution to the "Free Rider" Problem. Econometrica. 45, 783.

Hanemann, W. M., 1991. Willingness to pay and willingness to accept: How much can they differ? American Economic Review 81(3), 635-647.

Horowitz, J. K., and K.E. McConnell, (2002). A review of WTA/WTP studies. Journal of Environmental Economics and Management. 44, 426-447.

Kahneman, D., J. L. Knetsch and R. H. Thaler, (1990). Experimental tests of the endowment effect and the Coase Theorem. Journal of Political Economy 93, 1325-1348.

Lomborg, B. (2001). The Skeptical Environmentalist: Measuring the Real State of the World. Cambridge University Press: Cambridge.

Plott, C.R., and K. Zeiler (2007). Exchange Asymmetries Incorrectly Interpreted as Evidence of Endowment Effect Theory and Prospect Theory? American Economic Review 97, No. 4, (September). 
Samuelson, P.A. (1954). The Pure Theory of Public Expenditures. Review of Economics and Statistics. 36: 387-389.

Sugden, R., (1999). Alternatives to the neoclassical theory of choice. Chapter 6 In: I. Bateman and K.G. Willis (Eds.). Valuing Environmental Preferences: Theory and Practice of the Contingent Valuation Method in the US, EU, and Developing Countries, Oxford University Press, pp. 152180.

Tversky, A. and D. Kahneman (1991). Loss aversion in riskless choice: A reference-dependent model. Quarterly Journal of Economics 104(4), 1039-1062. 


\section{Figure 1. True Versus Apperent Public Good Optima}

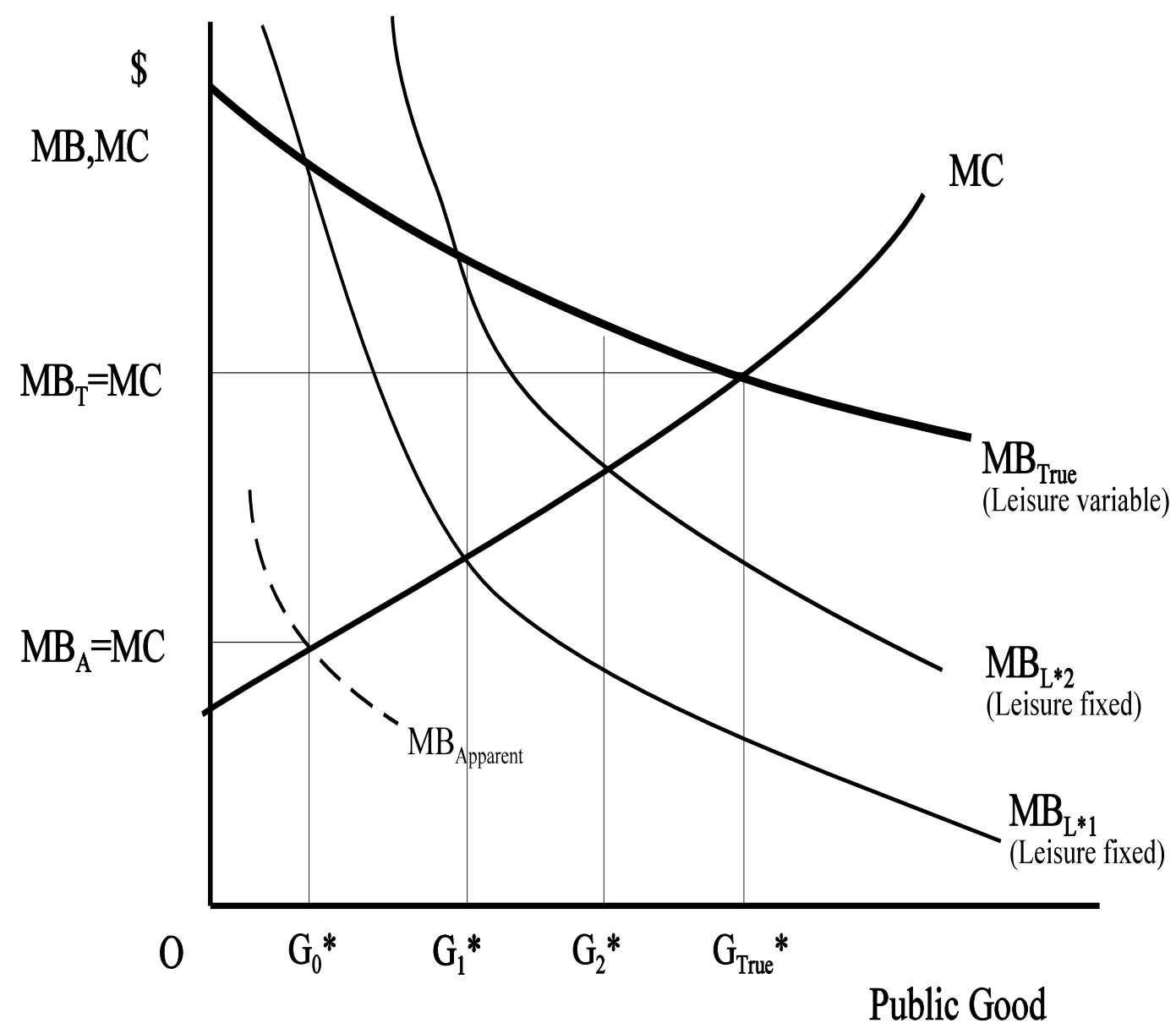

